\title{
As convenções jornalísticas e a verbo-visualidade do jornal impresso entre tensionamentos
}

\author{
Phellipy Pereira Jácome \\ Doutor; Universidade Federal de Minas Gerais; Belo Horizonte, MG, Brasil \\ phellipy@ufmg.br
}

Bruno Souza Leal

Doutor; Universidade Federal de Minas Gerais; Belo Horizonte, MG, Brasil brunosleal@gmail.com

\section{Resumo}

Neste artigo, discutimos a verbo-visualidade do jornal impresso, tendo como foco principal o papel comunicativo das convenções jornalísticas. Essa discussão se ancora numa noção ampliada de texto, buscando perceber seus aspectos configurantes e pragmáticos. As convenções se apresentam como um ponto de articulação entre padrões sedimentados de um fazer jornalístico, intimamente ligados às dinâmicas culturais e comunicacionais que situam produtos e processos historicamente, e os modos como cada mídia informativa emerge na regular singularidade de uma edição peculiar. Nessa perspectiva, a ideia de identidade de uma dada mídia informativa e mesmo das notícias que ela reporta adquire novos contornos, revelando uma qualidade fortemente performativa e em constante negociação.

\section{Palavras-chave}

Convenções. Textualidade. Verbo-visualidade. Cultura Visual. Jornalismo Impresso.

\section{Introdução}

A pergunta "por que as notícias são como são" tem guiado, no início do século XXI, vários estudos relacionados ao jornalismo (PENA, 2005; TRAQUINA, 2005; SOUSA, 2002, 2005). Em defesa desse tipo de teorização, Jorge Pedro Sousa (2005, p. 74), por exemplo, defende que "[a] teoria do jornalismo deve ser vista essencialmente como uma teoria da notícia, já que a notícia é o resultado pretendido no processo jornalístico de produção da informação". De maneira similar, Felipe Pena (2005, p. 18) afirma que a pergunta mais importante para uma teoria do jornalismo deveria ser "[..] qual o critério utilizado pelos 
profissionais da imprensa para escolher que fatos devem ou não virar notícia". A busca por critérios de noticiabilidade certamente é importante. No entanto, igualar as dimensões simbólicas e processuais das práticas e textualidades jornalísticas à "notícia" como seu único resultado pretendido nos parece ser uma redução, na medida em que obnubila uma reflexão mais ampla acerca do jornalismo - suas dimensões sensíveis e afetivas, inclusive - que existe para além dela (BERGER; TAVARES, 2010; NERONE, 2013; LEAL, 2009; JÁCOME, 2017). Essa sobreposição entre jornalismo e notícia, assim, só pode ser conquistada a um custo histórico muito alto. Afinal, a própria diversidade dos jornais (em suas mudanças e clivagens, como editorias e seções, e nas próprias notícias que apresenta) e do jornalismo (nas várias formas, processos e transformações) parece ser posta em suspenso.

Além disso, nesse tipo de perspectiva parece perdurar a ideia de uma suposta passividade textual, em que a notícia, reveladora de uma busca jornalística pela atualidade e pela novidade, poderia ser igualada aos fatos que ela reporta. Entretanto, como ressalta Leal (2002, p. 1), por mais paradoxal que possa parecer, o jornalismo, tido comumente como veiculador do novo, depende substancialmente de uma relação familiar e, até mesmo, repetitiva. "Afinal, como produto comercial, a notícia pressupõe um hábito de consumo, estruturada que é em torno da regularidade em que é posta em circulação". Assim sendo, para que a notícia seja oferecida como uma narrativa do real, é necessário que certos procedimentos sejam naturalizados, tornando familiares as formas pelas quais o jornal configura a realidade. $\mathrm{E}$ isso só é possível a partir do contato periódico entre o leitor/ouvinte/espectador e as mídias noticiosas, para que o mundo narrativo ofertado pelo jornal possa ser reconhecível, tornado comum e naturalizado.

Desse modo, por mais que o "objeto" da notícia possa ser diferente, é necessário que a mídia informativa assegure ao seu leitor/ouvinte/espectador que, a cada edição,"[d]o outro lado da primeira página, o jornal continua o mesmo, com seus cadernos, rubricas e colunas que o leitor já conhece bem, adquirindo, na sua diversidade, um estilo próprio, fundamento das múltiplas identificações" (FRANÇA, 1998, p. 132). É nesse sentido que, para assegurar sua eficácia, a textualidade jornalística necessita mobilizar certos pressupostos e modos de constituição de narrativas familiares aos esquemas de real sedimentados numa comunidade interpretativa (JÁCOME; LEAL, 2013).

Neste artigo, exploramos papéis que as convenções gráficas de jornais impressos estabelecem na apresentação das notícias, o que expõe a tensão entre repetição/novidade típica dos produtos jornalísticos. Essa exploração se baseia numa noção ampliada de texto e suas implicações para os estudos dos processos de produtos comunicacionais, a partir do que indicam trabalhos como os de Abril (2007), Jácome (2015) Manna (2017), Leal, 
Carvalho e Alzamora (2017 e 2018). Entendido não como um dado, mas como um resultado acabado de uma cadeia produtiva e comunicativa linear, o texto é tomado aqui como textualidade, ou seja, como um processo multidimensional, multimodal e no qual atuam diferentes agentes. As convenções se apresentam então como um ponto de articulação entre padrões sedimentados de um fazer jornalístico, intimamente ligados às dinâmicas culturais e comunicacionais que situam produtos e processos historicamente, e os modos como cada mídia informativa emerge na regular singularidade de uma edição peculiar. Nessa perspectiva, a ideia de identidade de uma dada mídia informativa e mesmo das notícias que ela reporta adquire novos contornos, revelando uma qualidade fortemente performativa e em constante negociação.

\section{Convencionalidades jornalísticas, uma aproximação}

A palavra "convenção", de acordo com o dicionário Houaiss, remete ao núcleo de sentido de "acordo", de prática regulada por entendimento mútuo ou por norma social. Esse núcleo se desdobra então nas acepções de práticas, recursos e/ou técnicas adotadas numa dada atividade e também na de uso e costume social estabelecido. Assim, na ideia de convenção estão contidas simultaneamente uma prática regular, adotada em relação a um dado material (como a linguagem, por exemplo) e uma dimensão social que a justifica e que lhe atribui razão de ser. Nessa perspectiva, adjetivos como "textual" ou "social" não indicam exclusões, retirando do termo uma ou outra dimensão, antes marcam um esforço de ressaltar, de privilegiar sem apagar, um aspecto já contido no núcleo de sentido básico do termo.

Não é à toa que diferentes trabalhos, de filiações teóricas diversas que se dedicam de algum modo ao estudo das convenções, ressaltam e se interessam exatamente por esse duplo alcance. Juliana Gutmann (2012, 2014a; 2014b; 2017), por exemplo, tem desenvolvido um conjunto de investigações sobre as formas do telejornal e outros produtos televisivos que demonstram a articulação entre materialidades textuais específicas e matrizes culturais mais amplas. Seus trabalhos, que ao mesmo tempo se baseiam e buscam operacionalizar o mapa das mediações de Jesus Martín-Barbero, têm na observação de formas regulares, de elementos recorrentes dos formatos, um ponto importante para articular, nas materialidades textuais, ritualidades e tecnicidades culturais. Assim, num estudo sobre os enquadramentos dos telejornais brasileiros, por exemplo, eles são tomados como "competências de linguagem, como materialidades que remetem à constituição de 
gramáticas dos telejornais" (2012, p. 65), ou seja, como formas que emergem e se justificam não apenas pelos protocolos "internos do jornalismo", mas por valores que perpassam a instituição jornalística, suas demandas comunicacionais, seu esforço de reconhecimento social. Em suma, por sua inserção em uma matriz cultural.

Já num estudo sobre as performances dos repórteres nos telejornais, a mesma autora observa que essas são "[p]ensadas enquanto estratégias de presentificação, o que supõe competências do leitor...", o que explicita que “[o] acesso aos acontecimentos é dado por essas camadas de mediação, conformadas por dispositivos expressivos como voz, gesto, posicionamento de câmera, figurino, transmissão direta, etc”. (2014b, p. 112). Para Gutmann, portanto,

\begin{abstract}
...o telejornal é um formato cujas tecnicidades são as formas materiais de lidar com os valores jornalísticos na TV (as gramáticas discursivas) e as ritualidades são os modos de constituição de um lugar de interação com o público (as gramáticas de uso).[...] A interpretação de como os corpos, enquanto tecnicidade, ritualizam modos de se relacionar com a notícia prevê, por exemplo, a consideração de valores instituídos do jornalismo e suas relações com modos de vida de uma dada coletividade, seus gostos, seus hábitos, suas relações com territorialidades (2014b, p. 111)
\end{abstract}

Ainda que nesses trabalhos referidos Gutmann não use a palavra "convenção", a sua atenção às formas e às gramáticas do fazer e do uso se integram a um olhar investigativo que explicita as dinâmicas comunicativas e culturais que dão sentido e razão de ser a modos regulares, recorrentes das textualidades das notícias e dos telejornais. Se as investigações da autora se posicionam claramente na matriz teórica dos Estudos Culturais, o semioticista italiano Ugo Volli (2007), por sua vez, sintetiza conclusões próximas a da pesquisadora brasileira a partir dessa outra linha de estudos.

Num breve ensaio sobre a "informação jornalística", Volli afirma que a notícia, em seus aspectos narrativos e discursivos, obedece a padrões, a regras comunicativas que, transcendendo a emergência de um texto noticioso singular, estão vinculados ao jornalismo como um fenômeno inserido numa dinâmica cultural mais ampla. Assim, diz Volli que as mídias informativas não fazem “...atribuições de sentido únicas para acontecimentos únicos, mas avaliações e interpretações mais globais, válidas para eventos considerados pertencentes a uma mesma classe, portanto, 'semelhantes'” (2007, p. 257, grifos do autor). Ele observa então que os "efeitos de verdade" buscados pela instituição jornalística tem sua construção “[...] absolutamente independentemente do seu grau de 'sinceridade' ou de 'confiabilidade informativa'. Depende muito, por outro lado, exatamente das opções referentes aos modos de 
representação, dentro do mesmo texto jornalístico, da relação entre os dados informativos e a construção do discurso" (2007, p. 260, grifos nossos). Situado numa tradição de estudos semióticos, Volli acentua, portanto, o quanto o jornalismo depende, para sua organização do mundo e eficácia comunicacional de padrões, regras, modos de representação que, novamente, transcendem uma dada notícia e posicionam o fazer jornalístico em meio a valores e disputas histórico-sociais.

Nesse breve incurso em trabalhos de matrizes tão diversas, parece-nos claro que as convenções jornalísticas, ao mesmo tempo culturais, comunicacionais e textuais, são também historicamente situadas. Os recursos narrativos televisuais identificados por Gutmann e mesmo os "modos de representação" reconhecidos por Volli estão articulados menos a uma "essência" ou identidade estável dos processos midiáticos e mais às necessidades impostas pelas transformações e demandas (comunicacionais, culturais, textuais, etc) que configuram e marcam uma dada realidade histórica. Em função dessas transformações, uma convenção pode se esgotar ou perder sua força e outras podem surgir, como aquelas que materializam o esforço televisual de proximidade com o telespectador. Nessa perspectiva, ainda que o ponto de ancoragem de estudos específicos, como este nosso, seja as convenções, seu horizonte é sempre a convencionalidade. Em outras palavras, as reflexões têm como problema não a simples caracterização de padrões e recursos estáveis, mas os modos temporalmente circunscritos em que uma dada convenção emerge, se mantém e/ou atua.

\section{A forma em ato}

No caso do jornalismo impresso, a conformação verbo-visual de uma mídia noticiosa surge como algo tão importante para dar unidade e tornar identificável o que poderia ser uma coleção dispersa, tanto no interior de cada mídia informativa, que reúne um conjunto aparentemente disperso de notícias particulares, com suas imagens, fontes, etc., como na sucessão periódica de seus números diários. É através das marcas de enunciação, que envolvem a diagramação e um estilo próprio de construção da notícia, que o jornal gera um padrão verbo-visual que o identifica. Por isso, “[...] não há certamente a novidade absoluta nem a redundância excessiva, mas o novo é tornado visível a partir da repetição de fórmulas narrativas, colunistas, espaços, jornalistas, padrão visual, etc." (LEAL, 2002, p. 2).

Isso porque a organização de nossa percepção visual é fator determinante para a configuração dos acontecimentos pelo jornal e por sua disposição nas páginas da mídia 
noticiosa. Afinal, a verbo-visualidade, culturalmente assentada, ordena nossa visão e nos oferece modos privilegiados de leitura e interpretação. Exemplo disso é que, como destaca Gonzalo Abril (2003), a modularização típica do jornalismo moderno é um amplo processo que tem a ver com a imprensa e a possibilidade de aproveitar os espaços e a distribuição das unidades informativas para racionalizar os recursos do processo produtivo e capturar o interesse do leitor (ABRIL, 2003, p. 92). Por isso, não é gratuita a recorrência e repetição de certos esquemas verbo-visuais no jornalismo. A familiaridade propiciada pelo acomodamento desses esquemas contribui para suavizar a leitura, o que é importante para um texto que necessita configurar realidades a partir de padrões socialmente sedimentados. Em relatos com pretensões realistas, como costuma ser o jornalismo, a coerência interna, fruto das convenções (simultaneamente comunicativas e textuais), é um importante elemento na configuração da referencialidade. Tais convenções, bem como seu aprendizado, contribuem no processo de naturalização e de oferta como "transparência". Isto é, num jornal estamos diante de inúmeras unidades informativas, cuja apreensão é assegurada também pela repetição de certos padrões textuais para garantir os pretendidos efeitos de real.

Essa forma em ato, como ressalta Moura (2010, 2013), serve como uma moldura, um suporte vivo para organização do novo, funcionando como uma proposta interpretativa, que garante unidade aos planos argumentativos e seus recursos retórico/verbais e estético/visuais. Isso tem a ver também com a existência de um público capaz de experimentar esse tipo de formato e realizar operações cognitivas particulares a partir dele. Ao ser criado um modo específico de agenciamento dos acontecimentos, temos abertas as maneiras peculiares de compartilhamento e experimentação daquele mundo narrativo. Em se tratando de jornalismo, o reconhecimento da formatação da mídia informativa, da disposição espacial dos seus elementos, "[...] surge do saber compartilhado entre sujeitos que conhecem a intenção, o papel informador do jornal e o anseio informativo do leitor" (MOURA, 2010, p. 173).

Assim, é preciso que haja um certo "saber-leitor" que valide as informações jornalísticas também pelo seu formato. Esse saber-leitor, aprendido no bojo de uma cultura midiática, é que faz com que possamos reconhecer que, ao ler uma capa de um jornal, teríamos contato com os principais assuntos abordados naquela edição. E que, além disso, esses assuntos deveriam ser desenvolvidos no interior do veículo. É o saber-leitor que indica também que o editorial seria a parte em que a mídia noticiosa deveria emitir sua opinião de maneira mais explícita, ou que nas erratas ele se redimiria de informações equivocadas de edições passadas. Esse mesmo conhecimento de leitura sedimentado faz com que alguém 
possa separar os distintos elementos verbo-visuais de uma mesma página e, ao mesmo tempo, gerar uma significação coesa. Assim, esse mesmo leitor é capaz de relacionar a manchete com aquilo que vem exposto logo abaixo dela, ou uma foto com a unidade que está localizada na sua parte inferior e que é tomada como legenda.

Na verbo-visualidade jornalística há, nesse sentido, uma série de convenções que compõem uma relação de produção e de consumo que pretende manter e conservar a mirada sobre si, gerando o efeito de que aquele modo de apropriação e leitura é tão "natural" e especular quanto ao discurso que se pretende apresentar. Entretanto, o que percebemos são estratégias textuais assentadas numa estabilização de unidades informativas que vão adquirindo funções específicas naquele entramado. Nesse ponto, a modularização possui um papel fundamental, pois como ressalta Abril (2003), possui duas funções axiais: uma relevância no nível estético (proporciona unidade à percepção da obra), como também no plano instrumental (facilita a distribuição de trabalho e torna possível a gestão industrial). Ou seja, a divisão da página em módulos permite a confecção de diferentes "retângulos", que marcam a separação entre uma notícia da outra, das diferentes colunas textuais, além de permitirem uma maior divisão e racionalização da produção, já que cada profissional poderá saber quantas linhas tem de escrever, se no espaço destinado à matéria que produz cabe uma foto, uma ilustração etc. Como aponta Moura,

Os vários elementos da materialidade verbal e visual do jornal são articulados modularmente nas páginas, vertical e horizontalmente, de modo a abrir possibilidades de relações de sentido diversas, porque o movimento encadeador das linguagens verbal e visual cria relações sintagmáticas no âmbito da experiência visual, que, por sua vez, é dimensionada por relações rítmicas estabelecidas a partir da sincretização verbo-visual. (MOURA, 2010, p. 97).

Por isso, na página de um periódico podemos perceber uma relação estratégica entre as diferentes unidades informativas que compõem uma mesma notícia (que, por sua vez, marcam a diferença desta com as demais). Essa relação modular prevê a utilização de elementos diferenciais e integradores, tais quais a colunagem, a cor, o espaçamento entre linhas e blocos textuais, a definição dos caracteres tipográficos, os recursos imagéticos etc. Além disso, planos de enunciação verbais e não-verbais são mobilizados em conjunto, se interpenetram. Beth Brait (1996) afirma que isso pode ser constatado tanto na organização dos cadernos e das páginas, como na diversidade de tipos e tamanhos de letras utilizadas, mas também nas diferentes combinações que envolvem texto-foto, foto-legenda, etc. 
Segundo a autora, tais elementos caracterizam e são caracterizados por estratégias discursivas constituídas ao longo da história do impresso e que não podem ser negligenciadas da análise. Isso porque a disposição dos elementos verbo-visuais a partir de uma padronização gráfica garante unidade aos planos argumentativos do periódico, conferindo-lhe uma identidade específica que, em contato com o mundo do leitor, se oferece como cotidiana e familiar. $4 \mathrm{~A}$ forma de um jornal ou do jornal?

A partir do que postulam e analisam Abril (2007), Moura (2010) e Brait (1996), portanto, pode-se observar que a escolha de cada um desses elementos composicionais organiza o real configurado pelo periódico e incide diretamente na relação entre o leitor e o corpo sensível do jornal. Isso é importante para a produção simbólica do real no jornalismo, já que representa a organização dos fragmentos da realidade, ou seja, uma tessitura que regula o mundo possível configurado e ofertado ao leitor. Visto isso, observemos algumas generalidades a partir do exemplo de um jornal de referência:

Figura 1 - Exemplo de verbo-visualidade do jornal $O$ Tempo

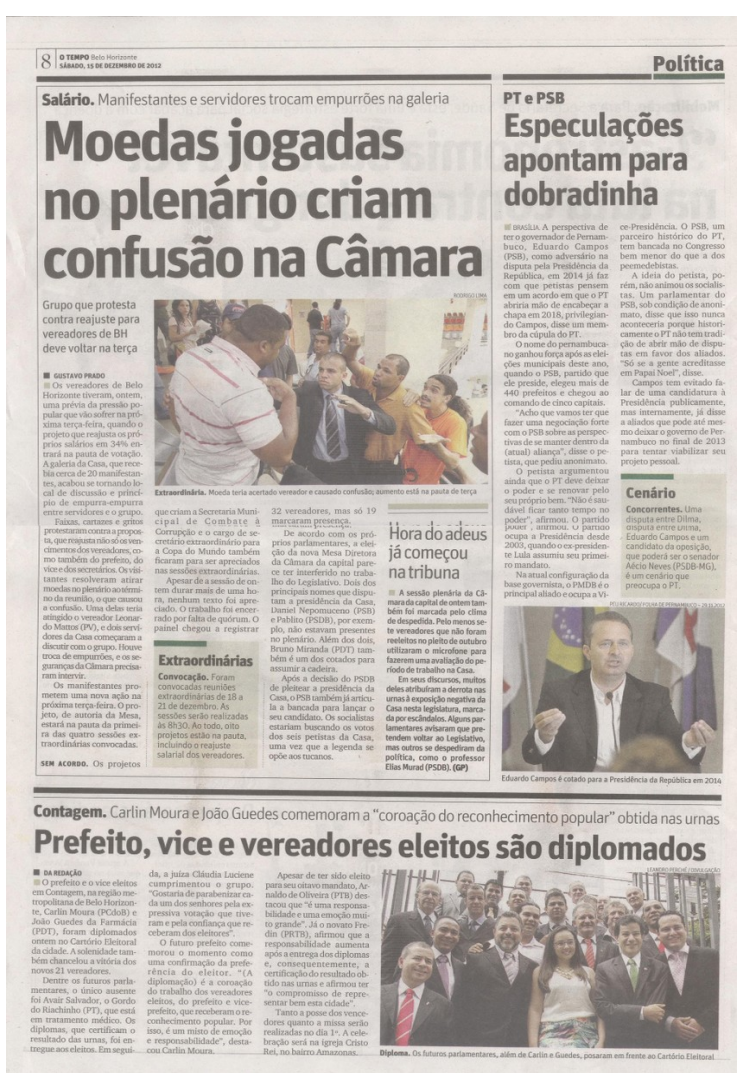

Fonte: Edição de 19/12/2012

Na página oito da edição de 19 de dezembro de 2012 do jornal $O$ Tempo, por exemplo, podemos identificar claramente que a página é composta por três notícias. Uma 
primeira, localizada à esquerda, recebe destaque pelo tamanho de mancha que ocupa, bem como por possuir um título com letras em maior dimensão do que as restantes. As outras duas matérias estão localizadas à direita e abaixo da matéria principal. Podemos notar que as unidades informativas de ambas estão alocadas num retângulo, que servem para integrar seus elementos num mesmo nível simbólico e separá-los dos outros módulos existentes na página. Esses fios da diagramação regulam a leitura e impedem uma confusão entre os diversos elementos semióticos que compõem a página, contribuindo para seu plano expressivo. Tal disposição retangular agrupa as unidades informativas coerentemente além de permitir que o leitor identifique rapidamente os módulos e elementos específicos de cada matéria.

Interessante perceber que um mesmo padrão visual se mantém entre um número e outro do jornal, evidenciando aquilo que havíamos argumentado anteriormente: que a modularização funciona tanto para o reconhecimento do leitor, quanto para os processos de racionalização. É como se o periódico fosse um grande palimpsesto, no qual as "novas" notícias se inscrevem no seu "habitual" formato. Isso dá mostras de como o jornalismo "molda" o acontecimento e propõe sua percepção a partir da familiaridade e das convenções textuais ligadas. Note que na página seis, só que da edição de 15 de dezembro de 2012, a disposição dos elementos verbo-visuais é rigorosamente a mesma.

Figura 2 - Verbo-visualidade comparada de $O$ Tempo
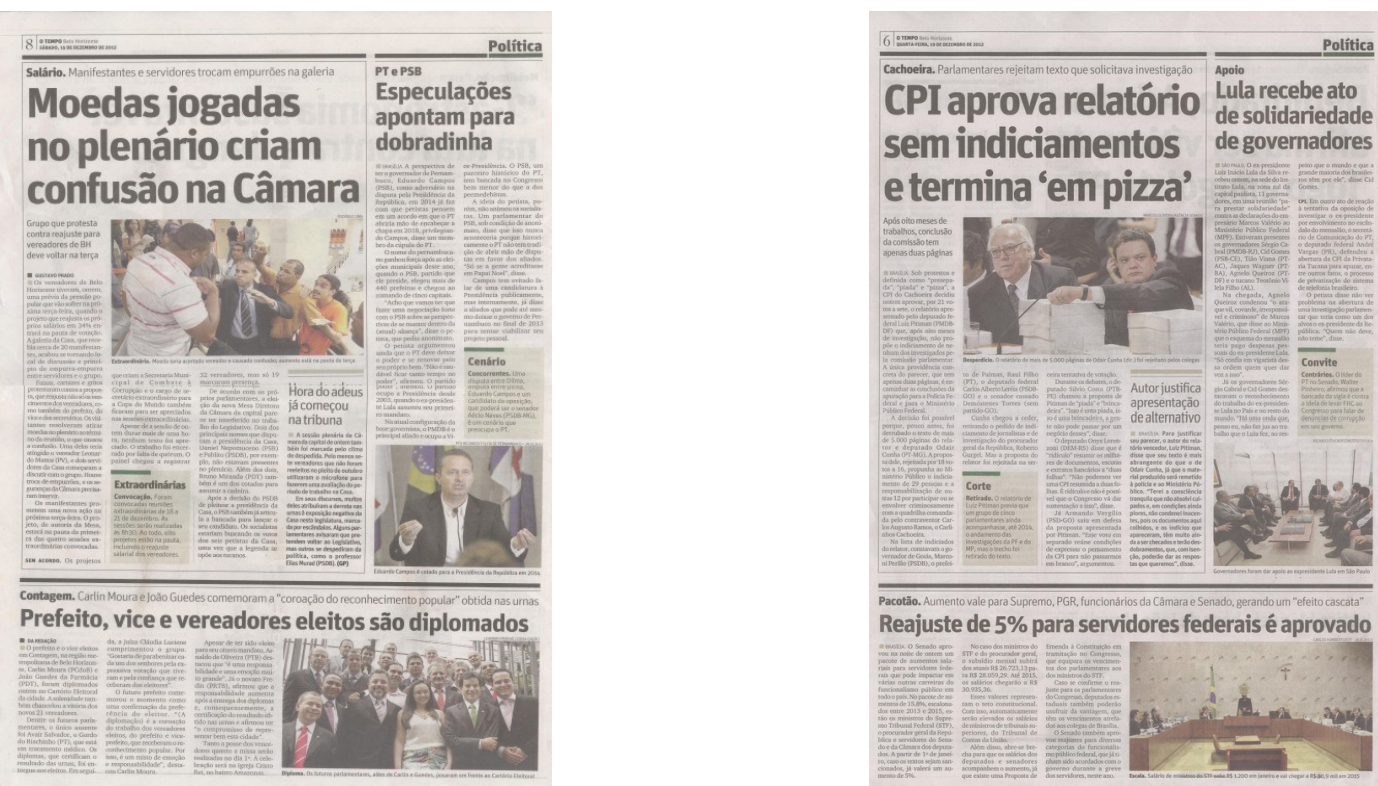

Fonte: Edições do jornal $O$ Tempo (19 e 15 de dezembro de 2012)

Tanto em um quanto noutro número do jornal (ou nas outras edições anteriores e posteriores que seguem o mesmo planejamento visual) podemos perceber a recorrência de 
unidades informativas alocadas numa mesma posição, em que uma parece substituir a outra, apagando-a a cada novo número da coleção. De fato, a consistência entre os elementos verbais e não-verbais num jornal é uma estratégia fundamental para tornar o texto mais ameno e familiar, numa tentativa de se superar a artificialidade da forma, ou fazer o leitor fruir através dele sem sobressaltos ou opacidade.

Nesse sentido, os modos de disposição verbo-visual, oriundos de processos históricos atualizados pelas obras específicas orientam e convocam determinadas estruturas ou padrões de tessitura das estruturas para inscrevê-las em uma expressão, propondo uma configuração textual da realidade, sugerindo e antecipando a refiguração. Isso denota aspectos de uma ampla cultura visual, que interliga visualidade, mirada e imagem (ABRIL, 2003). Afinal, é possível perceber em jornais ocidentais aspectos de uma "alfabetização mediática", já que, por exemplo, podemos saber quantas notícias nos brinda um periódico grego, ainda que não saibamos o alfabeto grego:

Figura 3 - Verbo-visualidade do diário grego TA NEA

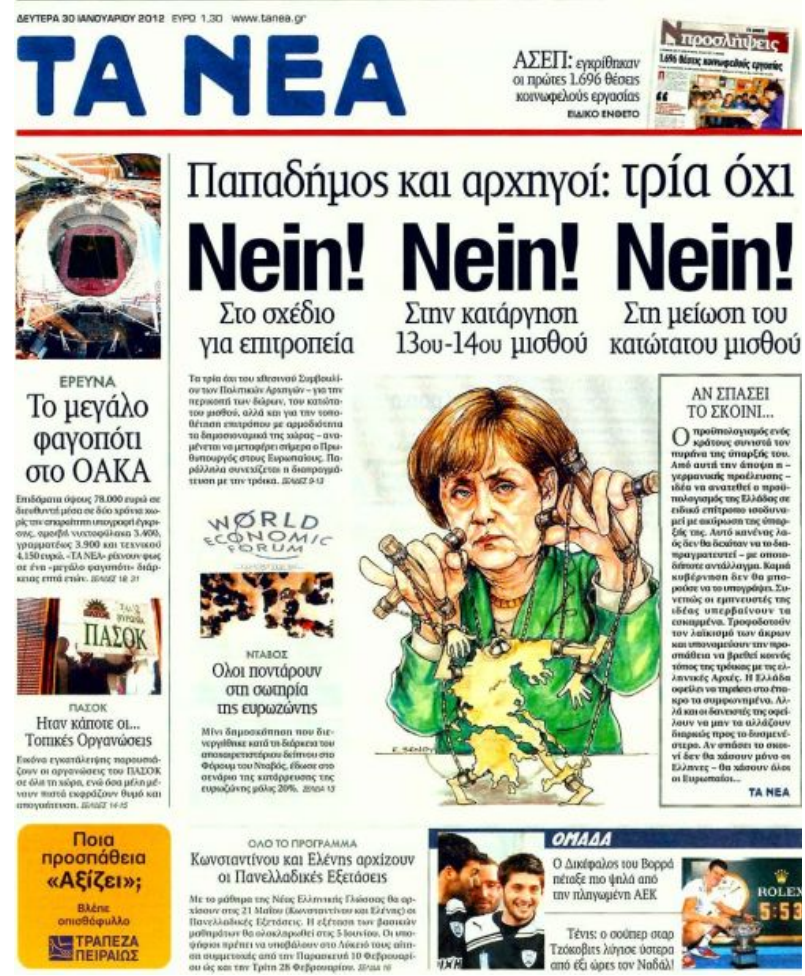

Fonte: Site oficial do jornal TA NEA (2018)

Na imagem acima, podemos identificar claramente onde está o nome do jornal, qual a manchete principal, quantas notícias traz a capa e, até mesmo, desconfiar que a unidade informativa alocada na parte superior direita do jornal (ao lado do nome do periódico) parece sugerir um suplemento ou especial, etc. Isso deixa entrever o estabelecimento de um 
padrão verbo-visual jornalístico comum. Tal padrão implica na circulação e no compartilhamento de convenções, numa "gramática" e ou "alfabetização" midiática para além das fronteiras nacionais.

Algumas das gramáticas e códigos já estão tão enraizadas que passam a ser tomadas como "naturais", como se fossem capazes de eliminar a distância entre as palavras e as coisas. Isso porque no nosso esforço de compreensão e comunicação, ainda que nos utilizemos largamente de tais convenções, na maioria das vezes, desconsideramos uma reflexão sobre o "funcionamento" delas. Quando abrimos um jornal, por exemplo, geralmente não temos que fazer grandes ponderações acerca do nosso movimento de leitura da esquerda para direita, de cima para baixo. Simplesmente lemos como aprendemos que deveria ser lido. Tampouco nos preocupamos em refletir que é da junção das diferentes letras tais como F, I, C, Ç, Ã, O que produzimos diversas palavras e que distintos sinais gráficos colocados acima dessas letras nos levarão a uma sonoridade específica e não a outras. Os processos de "alfabetização" nos ajudam a "ler" tais convenções, avançando sobre elas e apagando-as, em favor das "realidades" que delas refiguramos (JÁCOME, 2015).

Entretanto, por mais que o jornalismo tente postular-se como um reprodutor de fatos, entre o mundo configurado pelas narrativas jornalísticas e o mundo refigurado pela experiência do leitor há sempre o surgimento de algo novo, já que quaisquer narrativas produzem também zonas de indeterminação, espaços a serem preenchidos e modificados pela instância leitora. Entre a configuração proposta pela materialidade verbo-visual do jornal e o mundo da experiência do leitor, haverá sempre espaços de inadequação e de reordenamento. No entanto, como bem pontua Moura,

\begin{abstract}
diferentemente da literatura, em que a indeterminação é valor positivo, no jornalismo ela é considerada aberrante, embora esteja radicada em sua materialidade constitutiva por meio dos implícitos, dos não ditos, através dos quais o mundo fenomênico (natural), insistente, se infiltra nas dobras, nas sombras, nos pontos de fuga do jornal. E é por meio deles que o leitor recupera os efeitos de sentido e reconhece a perspectiva enunciativa do sujeito semiótico jornal(MOURA, 2010, p. 155).
\end{abstract}

Desse modo, o percurso que viemos conduzindo até agora sugere que as narrativas jornalísticas estão assentadas em processos de sedimentação e de familiaridade, fundamentais para a criação da confiança. Assim sendo, a indeterminação e os não-ditos na linguagem podem ser considerados problemáticos para uma visão de jornalismo, já que, ao extremo, podem revelar a linguagem como construção, desnaturalizando o mundo 
configurado em suas páginas. 0 texto não é somente uma tessitura "interna" de qualidades e acontecimentos semióticos. É também um tecido mais amplo, espacial, temporal e culturalmente reconhecível. Por isso, atua com outros textos e só é objetivável em seu processo interpretativo, isto é, na experiência de sua leitura e de suas condições socioculturais (ABRIL, 2012, p. 1.). Nesse sentido, o texto está embebido de uma "textualidade", ligado a várias redes interpretativas. Isso significa dizer que há, como postula Abril, uma relação entre "intertextualidades generalizadas" e as "engrenagens" do texto na práxis discursiva, motivo pelo qual ele só pode ser entendido em termos sociais/culturais/históricos. Os exemplos mobilizados no artigo são importantes para destacar que o texto deve ser entendido como um ato, uma prática sócio-discursiva oriunda de dimensões pragmáticas.

O texto jornalístico - suas notícias, inclusive - é sempre uma possibilidade e não deve ser reduzido às relações lógicas ou mecânicas. Isso porque o jornal se constrói verbovisualmente e se oferece como presença, um espaço de possibilidades de leitura para que o leitor rearticule as unidades informativas e as dote de sentido ao cruzá-las com sua experiência. A objetividade do texto, os regimes de verdade e a demarcação de fronteiras entre ficção e realidade, portanto, dependem menos de um suposto espelhismo textual, e muito mais de um esforço cooperativo entre os agentes envolvidos nos processos de significação, no qual as convenções, compartilhadas entre ambos, são fundamentais (JÁCOME, 2015).

Nessa perspectiva, a identidade de uma dada mídia informativa surge problemática e problematizável em mais de um nível. Por um lado, sendo o mesmo a cada edição, o jornal assenta sua identidade nas formas estáveis de sua textualidade e do repertório do seu leitor. Essa estabilidade, porém, é conseguida em certa medida pelo seu próprio pressuposto: pelo contato regular desse leitor com as formas regulares do jornal. Instaura-se assim um processo de constante negociação, em que a performance das convenções, a cada edição, atua para conformar e fazer avançar. Afinal, sendo o mesmo, o jornal precisa a cada emergência, ser outro. Essa negociação delicada não implica apenas a necessidade de "grampear" as "fraturas" e identidades internas do jornal (MOUILLAUD, 2002; LEAL; CARVALHO, 2012; JÁCOME; LEAL; MACIEL, 2013), nem fundar cada nova edição sob o prisma do mesmo, da repetição.

Ao nos atentarmos para a ambiguidade das convenções, a um lance textuais, comunicacionais e culturais, um jornal tem sua identidade simultaneamente dissolvida e alavancada pela própria instituição jornalística. A negociação de um jornal com seu leitor, na tensão entre novo e mesmo, não seria eficaz se não houvesse o acordo, o amparo dos outros 
jornais e das formas convencionais postas em circulação pelos demais agentes da comunidade jornalística. Nesse momento, a identidade editorial, de marca, de uma dada mídia noticiosa só se sustenta porque esta mesma mídia é mais uma a atualizar, a mobilizar as convenções, os modos de ser e fazer jornalístico. É dissolvendo-se como singularidade então que um jornal se afirma como mídia noticiosa, no interior da comunidade e da instituição jornalística. Ao mesmo tempo, sendo uma a mais, essa mesma mídia noticiosa adquire condições e parâmetros para se apresentar como uma única, singular, irrepetível na repetição particular que estabelece das formas e processos jornalísticos. Nesse jogo ambíguo, a identidade de uma mídia informativa específica adquire um caráter altamente performativo, sempre dependente dos modos como as convenções que mobiliza e em que se ancora são apreendidas e significadas pelos diferentes agentes que interagem na comunidade interpretativa que integra.

\section{Referências}

ABRIL, G. Análises crítico de textos visuales. Madrid: Síntesis, 2007.

ABRIL, G. Cortar y pegar: la fragmentación visual en los orígenes del texto informativo. Madrid: Cátedra, 2003.

ABRIL, G. Tres dimensiones del texto y de la cultura visual. IC: Revista científica de Información y Comunicación, Sevilla, n. 9, p. 15-35, 2012.

BERGER, C.; TAVARES, F. M. Na notícia e para além dela: sobre o conceito de informação no jornalismo. Informação \& Sociedade: Estudos, Paraíba, v. 20, p. 25-37, 2010.

BRAIT, B. Ironia em perspectiva polifônica. 2. ed. Campinas: Editora Unicamp, 2008. v. 1, $294 \mathrm{p}$.

FRANÇA, V. Jornalismo e vida social: a história de um jornal mineiro. Belo Horizonte: UFMG, 1998.

GUTMANN, J. F. O que dizem os enquadramentos de câmera no telejornal? Um olhar sobre formas audiovisuais contemporâneas do jornalismo. Brazilian Journalism Research , Brasília, v. 8, p. 64-79, 2012.

GUTMANN, J. F. Quando ruptura é convenção: 0 programa Gordo a Go-Go como espaço de experiência do talk show. Contracampo, Rio de Janeiro, v. 31, p. 61-78, 2014a.

GUTMANN, J. F. Entre tecnicidades e ritualidades: formas contemporâneas de performatização da notícia na televisão. Galáxia (São Paulo), São Paulo, v. 14, p. 108-120, 2014b.

JÁCOME, P. Fissuras no espelho realista do jornalismo: a narratividade crítica de Barcelona. Belo Horizonte: Selo PPGCom, 2015. 
JACOME, P. 0 jornalismo como singular coletivo: reflexões sobre a historicidade de um fenômeno moderno. 2017. Tese (Doutorado em Comunicação Social)- Faculdade de Filosofia e Ciências Humanas, Universidade Federal de Minas Gerais, Belo Horizonte, 2017.

JÁCOME, P.; LEAL, B. S.; MACIEL, W. Os jornais no jornal: o Meia Hora e suas faces. Intexto, Porto Alegre, v. 1, p. 58-78, 2013.

JÁCOME, P.; LEAL, B. S. Outros agentes na comunidade interpretativa do jornalismo. Rumores, São Paulo, v. 7, p. 45-61, 2013.

LEAL, B. S. A produção da familiaridade e o pacto de leitura jornalístico. Salvador: Intercom, 2002.

LEAL, B. S. Para além da notícia: o jornal, sua identidade, sua voz. Revista Fronteiras Estudos Midiáticos, São Leopoldo, v. 11, p. 113-123, 2009.

LEAL, B. S.; CARVALHO, C. A. Jornalismo e homofobia no Brasil. São Paulo: Intermeios, 2012.

LEAL, B. S.; CARVALHO, C. A. (org.).; ALZAMORA, G. (org.). Textualidades Mediáticas. 1. ed. Barcelona: UOC, 2017.

LEAL, B. S.; CARVALHO, C. A. (org.).; ALZAMORA, G. (org.). Textualidades Midiáticas. 1. ed. Belo Horizonte: Selo PPGCOM, 2018.

MANNA, N. Jornalismo e o espírito intempestivo: fantasmas na mediação jornalística da história, na história. 1. ed. PPGCOM UFMG, 2016. 296 p.

MOUILLAUD, M. 0 jornal: da forma ao sentido. Trad. Sérgio Gossi Porto. Brasília: UnB, 2002.

MOURA, Maria Betânia. Por uma teoria do formato jornalístico: reflexões sobre o jornal como sujeito semiótico. Belo Horizonte: Tese de doutoramento, 2010.

MOURA, M. B. Reflexões sobre o formato jornalístico: da "aparência" ao "aparecer". In: LEAL, Bruno Souza (org.).;CARVALHO, Carlos Alberto de (org.). Narrativas e poéticas midiáticas: estudos e perspectivas. São Paulo: Intermeios, 2013.

NERONE, J. The Historical Roots of the Normative Model of Journalism.Journalism 14:4. 2013: p. 446-58.

PENA, F. Teoria do jornalismo. São Paulo: Editora Contexto, 2005.

SOUSA, J. P. Construindo uma teoria multifactorial da notícia como uma teoria do jornalismo. Estudos Em Jornalismo, v. II, n. 1, p. 73-94, 2005.

SOUSA, J. P. Teorias da notícia e do jornalismo. Florianópolis: Letras Contemporâneas, 2002.

TRAQUINA, N. Teorias do jornalismo: volume I: porque as notícias são como são. Florianópolis: Insular, 2005.

VOLLI, U. Manual de semiótica. São Paulo: Loyola, 2007. 


\title{
Journalistic conventions and newspaper's verbal visuality under tensions.
}

\begin{abstract}
In this article, we discuss the verbal visuality of printed newspapers, having as main focus the communicative role of the journalistic conventions. This discussion is anchored in an expanded notion of text, seeking to perceive its configurative and pragmatic aspects. The conventions are presented as a point of articulation between sedimented patterns of journalistic newsmaking, closely attached to the cultural and communicational dynamics that situate products and processes historically. In this perspective, the idea of identity of a singular news outlet and the news that it reports acquires new contours, revealing a strongly performative quality and constantly negotiating.
\end{abstract}

\section{Keywords}

Conventions. Textuality. Verbal visuality. Visual Culture. Press.

Recebido em 25/05/2018

Aceito em 02/05/2019 